\title{
CACNA1D-mutatie veroorzaakt epilepsie, autisme en een verstandelijke beperking
}

Met de komst van nieuwe DNA-technieken zoals whole-exome sequencing neemt kennis over de genetische basis van ziekten zoals epilepsie snel toe. De interpretatie van genetische data is in de praktijk echter vaak complex. De hier beschreven casus toont hoe een nieuwe genmutatie na jaren een nieuw licht kan werpen op de diagnostiek en behandeling van een patiënt met een calciumkanalopathie.

Ionkanalopathieën worden veroorzaakt door genmutaties in spanningsafhankelijke ionkanalen en leiden tot symptomen door verstoring van de normale prikkelgeleiding in elektrisch-actieve weefsels. In de hersenen zijn voornamelijk natriumkanalopathieën verantwoordelijk voor epilepsie, met als bekendste voorbeeld het syndroom van Dravet (Spillane et al., 20r6). In deze bijdrage wordt de eerste Nederlandse epilepsiepatiënt met een calciumkanalopathie op basis van een mutatie in het CACNA1D-gen beschreven. Naast epilepsie kunnen autisme, een verstandelijke beperking, cardiale ritmestoornissen, congenitale doofheid en primair hyperaldosteronisme onderdeel zijn van het CACNA1D-fenotype (Pinggera et al., 20I7). We bespreken onze bevindingen aan de hand van het veronderstelde pathofysiologisch mechanisme en de eerder beschreven casuïstiek.

\section{Casus}

Een 3I-jarige man werd voor het eerst op 26-jarige leeftijd verwezen naar de polikliniek van Kempenhaeghe voor een tweede mening met als doel meer duidelijkheid te krijgen omtrent zijn epilepsiesyndroomdiagnose.

Uit de voorgeschiedenis bleek een ongestoorde perinatale periode bij een à terme geboorte zonder koortsstuipen, meningo-encefalitis of traumatisch hersenletsel in de vroegkinderlijke periode. Er was sprake van een ontwikkelingsstoornis in het autistiforme spectrum, gecombineerd met een stoornis in de motorische ontwikkeling, waarvoor hij op vierjarige leeftijd werd geanalyseerd. Op latere kinderleeftijd werden een autistiforme spectrum stoornis en een verstandelijke beperking vastgesteld zonder syndroomdiagnose.

In zijn puberteit ontwikkelde hij een tremor van de handen, hetgeen hem hindert bij eten en drinken. Propanolol gaf geen verbetering. Voorts kwamen ook andere intermitterende uitingen voor zoals motore onrust in de benen, rare gevoelens in het hoofd en stereotype slikbewegingen. De familie-anamnese is positief voor PDD-NOS en Gilles de la Tourette aan de kant van moeder, en essentiële tremor aan de kant van vader.

De epilepsie begon op 25-jarige leeftijd waarbij hij op één dag meerdere aanvallen kreeg: hij werd in de ochtend aangetroffen op zijn bed met stik-achtige geluiden en een blauw gelaat, waarna enkele minuten schokken optraden van de ledematen. Tevens werd een laterale tongbeet geconstateerd. Eenmaal in het ziekenhuis ontstond een serie focale aanvallen waarbij hij plotseling speeksel opgaf, kwijlde en moest braken, afwezig en motorisch onrustig werd, gevolgd door diepe slaap. Aan het eind van deze dag kreeg hij vanuit alerte toestand (niet voorafgegaan door braken of smakken) plotseling weer een gegeneraliseerde aanval met schokken waarop werd gestart met anti-epileptica. Achtereenvolgens werd over een tijdsbestek van een aantal jaar gestart met valprö̈nezuur (effectief maar gestaakt wegens leverfunctiestoornissen), levetiracetam (niet effectief), carbamazepine (gestaakt wegens dystone bewegingen van de ogen en diplopie) en tenslotte een combinatie van oxcarbazepine en clobazam. Hierop verdwenen de gegeneraliseerde aanvallen. De vaak in clusters voorkomende focale aanvallen met staren en forse autonome activatie (kwijlen, braken) bleven frequent aanwezig zowel vanuit waak als slaap. Vooral in september trad vaak een cluster gedurende bijna de gehele maand op. Een opvallend prodroom van de clusters focale aanvallen is een periode met polyurie. Een MRI van de hersenen toonde geen afwijkingen. Een 24-uurs video-EEG en meerdere routine-EEG's toonden (inter)ictaal nooit epileptiforme afwijkingen. 
Wel werd de aanvalsemiologie meermaals geobjectiveerd tijdens klinische opnames, waarbij tevens korte myoclone aanvallen van de mondhoek en linkerarm (met een duur van ro seconden) werden gezien in de vroege ochtend. DNA-diagnostiek in de vorm van een whole-exome sequencing toonde een nog niet eerder beschreven en zeer waarschijnlijk pathogene Ile77oVal missense verandering van het deels hersenspecifieke voltage-afhankelijke calciumkanaalgen (CACNA1D). Om te bepalen of de prodromen met polyurie worden veroorzaakt door een primair hyperaldosteronism passend bij de CACNA1D-mutatie werd extra aanvullend onderzoek gedaan: de bloeddruk was niet verhoogd op verschillende momenten van de dag en de elektrolytsamenstelling van het bloed en de nierfunctie waren onge- stoord. De uitslag van de renine en aldosteron serum bepalingen is nog onbekend.

\section{Beschouwing}

Het 'porie-vormende' deel van ionkanalen, waardoor de ionenstroom zich verplaatst onder invloed van spanningsverschillen, wordt de alpha-subunit genoemd. Deze alphasubunit komt grotendeels weefselspecifiek tot expressie doordat kleine variaties van het kanaal (isotypen genaamd) vaak exclusief, per weefsel, worden afgelezen vanuit een of meerdere genen. Hierdoor zijn symptomen van de meeste ionkanalopathieen ook veelal binnen één type weefsel te lokaliseren (bijvoorbeeld in het centraal zenuwstelsel of skeletspieren en hartspier) (Spillane et al., 20I6). Het

\begin{tabular}{|c|c|c|}
\hline CACNAID-genotype & Fenotype & Referentie \\
\hline $\begin{array}{l}\text { Val4oiLeu } \\
\text { (de-novo, missense, } \\
\text { gain-off-function) }\end{array}$ & $\begin{array}{l}\text { Neonatale neuromusculaire hypotonie, vertraagde motore } \\
\text { mijlpalen, autisme en agressie, opvallende manieren en motore } \\
\text { onrust van handen, romp en benen. Ernstige mentale retardatie. } \\
\text { Op 2-jarige leeftijd debuut epilepsie: focale aanvallen met bilateraal } \\
\text { tonisch-clonisch secundaire generalisatie. EEG: multifocale } \\
\text { interictale, epileptiforme afwijkingen. }\end{array}$ & Pinggera et al. 2017 \\
\hline $\begin{array}{l}\text { Gly403Asp } \\
\text { (de-novo, missense, } \\
\text { gain-off-function } \\
\text { mutatie) }\end{array}$ & $\begin{array}{l}\text { Neonatale hypertensie, biventriculaire hypertrofie, ventrikel- } \\
\text { septum-defect, pulmonale hypertensie, ze graads AV-blok, } \\
\text { primaire hyperaldosteronisme, epilepsie (niet verder gedefinieerd), } \\
\text { corticale blindheid, complexe neuromusculaire abnormaliteiten } \\
\text { (niet verder gedefinieerd). Lab: verhoogd serum aldosteron bij } \\
\text { verlaagde plasma renine activiteit. }\end{array}$ & Scholl et al. 2013 \\
\hline $\begin{array}{l}\text { Gly403Asp } \\
\text { (de-novo, missense, } \\
\text { gain-off-function } \\
\text { mutatie) }\end{array}$ & $\begin{array}{l}\text { Neonatale hyperinsulinaire hypoglycaemie, bradycardie en milde } \\
\text { aorta-insufficientie, hypermetropie, ernstige axiale hypotonie en } \\
\text { epilepsie (niet verder gedefinieerd) }\end{array}$ & Flanagan et al. 2017 \\
\hline $\begin{array}{l}\text { Ile77oMet } \\
\text { (de-novo, missense, } \\
\text { gain-off-function } \\
\text { mutatie) }\end{array}$ & $\begin{array}{l}\text { Neonataal spastisch bipiramidaal syndroom, milde athetose, } \\
\text { ernstige intellectuele beperking, epilepsie (focale en primair } \\
\text { gegeneraliseerde insulten). Vanaf } 5 \text { jaar hypertensie met al langer } \\
\text { polydipsie. Hypokaliemie en metabole alkalose. Verhoogd serum } \\
\text { aldosteron bij verlaagde plasma renine activiteit. } \\
\text { Familie-anamnese negatief. }\end{array}$ & Scholl et al. 2013 \\
\hline $\begin{array}{l}\text { Ile77oVal } \\
\text { (missense mutatie) }\end{array}$ & In dit artikel beschreven patiënt & $\begin{array}{l}\text { Stunnenberg et al. } \\
2018\end{array}$ \\
\hline $\begin{array}{l}\text { p.403_404insGlyl } \\
\text { p.403_404insGly } \\
\text { (homozygote, } \\
\text { loss-of-function insertie) }\end{array}$ & $\begin{array}{l}\text { Sinoatriale knoop dysfunctie en congenitale doofheid in twee } \\
\text { onafhankelijke families (in totaal } 7 \text { familieleden). }\end{array}$ & Baig et al. $201 \mathrm{I}$ \\
\hline
\end{tabular}

Tabel 1 Overzicht van in de literatuur gerapporteerde patiënten met een CACNA1D-genmutatie met beschrijuing van genotype en fenotype. 
CACNA1D-gen dat codeert voor isotype alpha-subunit Cavi.3 van het voltage-afhankelijke calciumkanaal vormt hierop de grootste uitzondering. Dierstudies tonen aan dat de expressie van Cavi.3 plaatsvindt in de hersenen en neuroendocriene klieren (zoals pancreas en bijnieren) en in mindere mate in de hartspier, skeletspieren, en cochlea (Williams et al., I992).

Opvallend is dat CACNA1D-mutaties zijn gevonden in operatief verwijderde bijnierschors-adenomen bij patiënten met therapieresistente hypertensie (Scholl et al. 2013). Deze mutaties blijken te berusten op een gain-of-function verandering leidend tot een toename in de geopende toestand van het kanaal en een meer gedepolariseerd membraan. Doordat het hormoon aldosteron vrijkomt onder invloed van calcium-geïnduceerde depolarisatie in de bijnierschors, wordt hiermee ook de therapieresistente hypertensie verklaard. Als nevenbevinding is er in twee patiënten, zonder bijnieradenoom maar met primaire hyperaldosteronisme, een kiembaanmutatie in het CACNA1D-gen aangetoond.

Het fenotype van deze twee eerste patiënten werd samengevat in het acronym PASNA (primaire hyperaldosteronisme, epilepsie (seizures) en neurologische abnormaliteiten in de vorm van autisme en gedragsstoornissen) en komt sterk overeen met het beschreven fenotype in de hier besproken patiënt. In tabel $\mathrm{I}$ is een overzicht gegeven van fenotype en genotype van alle in de literatuur beschreven CACNA1D-patiënten. CACNA1D-mutaties zijn ook gevonden in twee onafhankelijke families met sinoatriale knoop (node) dysfunctie en congenitale doofheid (SANDD) (Baig et al., 20II) en in een patiënt met neonatale hyperinsulaire hypoglycaemie, een bradycardie en epilepsie (Flanagan et al., 20I7). In figuur I is schematisch een overzicht gegeven van de in de literatuur beschreven CACNA1D fenotypische kenmerken.

We vermoeden dat de hier beschreven CACNA1D-verandering een pathogene mutatie is, omdat de tot op heden beschreven CACNA1D-mutaties, zoals weergegeven in figuur 2, op gelijke locaties worden gevonden als bij onze patiënt. Het resultaat van de segregatie-analyse bij de ouders is nog niet bekend. Deze is bedoeld om nog in om na te gaan of het hier een de-novo mutatie betreft. We overwegen een reeds eerder beschreven behandeling met calciumkanaalblokkers om gericht het specifieke defect aan te pakken, zoals eerder werd beschreven (Scholl et al. 2013).

\section{Conclusie}

Het gaat hier om de eerste Nederlandse epilepsiepatiënt met een calciumkanalopathie door een (zeer waarschijnlijk) nieuwe pathogene mutatie in het CACNA1D-gen met als fenotype epilepsie, autisme, gedragsstoornissen en mogelijk paroxysmale overprikkeling van de endocriene klieren (bijnierschors en speekselklieren). Voor zowel (kinder)neurologen, kinderartsen en artsen voor verstandelijke gehandicapten is het (her)kennen van dit zeldzame ziektebeeld met geassocieerde fenotypes van belang.

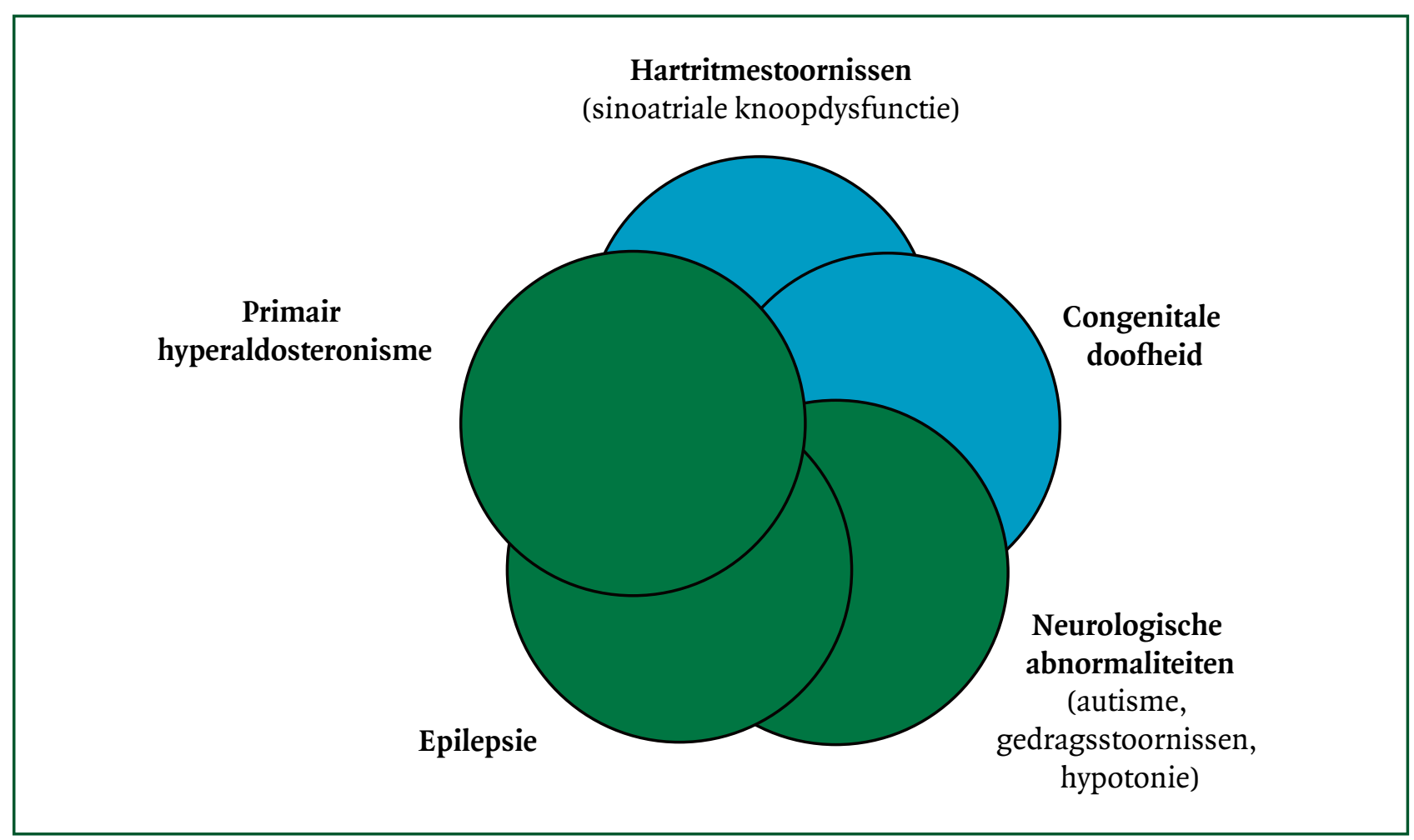

Figuur 1 Het brede klinisch spectrum aan klachten (fenotype) bij gerapporteerde patiënten met een CACNA1D-genmutatie, waarbij meerdere orgaansystemen betrokken zijn (hersenen, bijnier, skelet- en hartspier en cochlea). In groen wordt het fenotype aangegeven dat wordt aangeduid met het acronym PASNA, terwijl in blauw het fenotype is weergegeven dat wordt aangeduid met het acronym SANDD). 


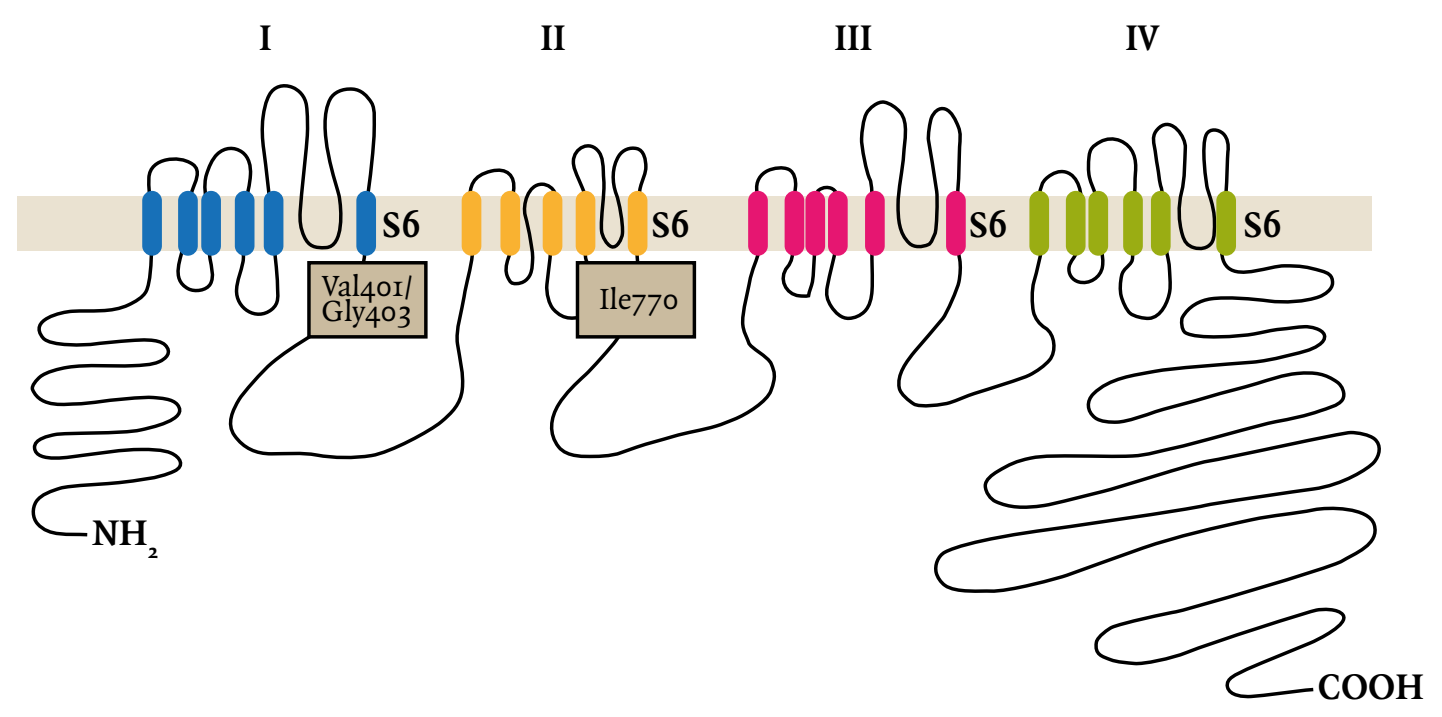

Figur 2 Schematische ('uitgeklapte') weergave van de ion-porie-vormende alpha-subunit van het voornamelijke hersenspecifieke voltageafhankelijke calciumkanaal. Getoond worden de vier membraangebonden domeinen (I t/m IV), elk bestaande uit zes transmembraanverbindingen ( $1 \mathrm{t} / \mathrm{m} \mathrm{S} 6$ ). De twee rode stippen tonen de locatie van de gemuteerde aminozuren in CACNA1D in het S6 segment van $\mathrm{D}_{1}$ (Val401 en Gly403) en DII (Ile770) die tot op heden in patiënten zijn beschreven. Deze S6 segmenten spelen een belangrijke rol in de langzame inactivatie van het kanaal.

\title{
Referenties
}

Baig SM, Koschak A, Lieb M et al. (20II) Loss of Ca(v)I.3 (CACNAID) function in a human channelopathy with bradycardia and congenital deafness. Nat Neurosci 14(1): 77-84.

Flanagan SE, Vairo F, Johnson MB et al. (2017) A CACNAID mutation in a patient with persistent hyperinsulinaemic hypoglycaemia, heart defects, and severe hypotonia. Pediatr Diabetes 18(4): 320-323.

Pinggera A, Mackenroth L, Rump A et al. (2017) New gainof-function mutation shows CACNAID as recurrently mutated gene in autism spectrum disorders and epilepsy. Hum Mol Genet 26(15): 2923-2932.
Scholl UI, Goh G, Stolting G et al. (2013) Somatic and germline CACNAID calcium channel mutations in aldosterone-producing adenomas and primary aldosteronism. Nat Genet 45(9): 1050-1054.

Spillane J, Kullmann DM, Hanna MG (2016) Genetic neurological channelopathies: molecular genetics and clinical phenotypes. J Neurol Neurosurg Psychiatry 87(1): 37-48.

Williams ME, Feldman DH, McCue AF et al. (I992) Structure and functional expression of alpha I, alpha 2, and beta subunits of a novel human neuronal calcium channel subtype. Neuron 8(1): 71-84.

\section{Epilepsiefonds}

\section{Nationaal Epilepsie Symposium}

\author{
I6 november 2018 \\ Jaarbeurs, Utrecht \\ Informatie: communicatie@epilepsiefonds.nl
}

